\author{
$4^{\text {th }}$ International Symposium on Flood Defence: \\ Managing Flood Risk, Reliability and Vulnerability \\ Toronto, Ontario, Canada, May 6-8, 2008
}

\title{
LOSS OF LIFE CAUSED BY THE FLOODING OF NEW ORLEANS AFTER HURRICANE KATRINA: A PRELIMINARY ANALYSIS OF THE RELATIONSHIP BETWEEN FLOOD CHARACTERISTICS AND MORTALITY
}

SN Jonkman ${ }^{1,2}$, B Maaskant $^{1,3}$, E Boyd $^{4}$, and M Levitan ${ }^{4}$

1. Delft University of Technology, Faculty of Civil Engineering and Geosciences, section of Hydraulic Engineering

2. Royal Haskoning, Coastal and Rivers Division

3. HKV Consultants, Risk and Safety Division

4. Louisiana State University, Hurricane Center

\begin{abstract}
In late August 2005, the New Orleans metropolitan area suffered the destructive power of hurricane Katrina. Large parts of the city flooded. This article utilizes the available data regarding Katrina related fatalities for Louisiana to analyse the relationship between flood characteristics and mortality. Available data regarding the recovery locations of Katrina related fatalities is presented and discussed. From this data, it is inferred that many, but not all, of the fatalities occurred inside the flooded areas. Insight in various characteristics of the flood has been gained based on available flood depth maps and hydrodynamic simulations that provide information in flood characteristics such as flow velocity, rise rate of the water and arrival time of the water. Combining the fatality data with the flood simulation results, the relationship between the flood characteristics and mortality is assessed. Similar to historical flood events, mortality rates were highest in areas near severe breaches and in areas with large water depths. Based on similar previous work (Jonkman, 2007) a relationship between mortality and flood characteristics is derived for the New Orleans data. It is important to note that the presented results and analyses for New Orleans are preliminary, but they give important insights in the relationship between mortality and flood characteristics.
\end{abstract}

Key Words: New Orleans; Katrina; Fatalities; Mortality; Flood risk; consequences.

\section{INTRODUCTION}

In late August 2005, the New Orleans metropolitan area suffered the destructive power of hurricane Katrina. Large parts of the city flooded after the system of levees failed and overtopped at several locations. This paper presents a statistical analysis of the relationship between flood mortality and flood characteristics, based on observational and simulation data from the heavily flooded parts of New Orleans.

The analysis focuses on loss of life in the flooded areas in the period during and shortly after the disaster. The presented results in this paper are based on the material presented in previous 
publications (Boyd, 2006; Maaskant, 2007; Jonkman, 2007). In addition to the initial loss of life, a recent analysis also provided insight on excess mortality associated with the longer term impacts of the disaster (Stephens et al., 2007).

\section{GENERAL INFORMATION REGARDING HURRICANE KATRINA}

Hurricane Katrina formed as a tropical storm in the Atlantic Ocean South East of Florida. The storm weakened slightly as it crossed Florida and entered the Gulf of Mexico on August 26 as a tropical storm. Katrina quickly regained hurricane status and it began to take aim for Southeast Louisiana. Between 26 and 28 August, the projected track shifted west and took aim for New Orleans. Shortly after New Orleans became a target, the storm strengthened to category 5. Peaking at 1:00 PM August 28 with maximum sustained wind speeds of $175 \mathrm{mph}(280 \mathrm{~km} / \mathrm{h})$ and wind gusts up to almost $220 \mathrm{mph}(350 \mathrm{~km} / \mathrm{h})$. Before making its second landfall near Buras, Louisiana, it weakened to a category 3 status with sustained winds of $125 \mathrm{mph}(200 \mathrm{~km} / \mathrm{h})$.

\subsection{Preparation: evacuation, shelter in place}

In the days before landfall, computer models predicted possible flooding of New Orleans. The first evacuation orders came early Saturday morning (August 27) for the outlying coastal areas, such as Plaquemines and St. Bernard. The next morning, shortly after Katrina was upgraded to category 5 strength and it was obvious that the storm posed a severe flood threat for New Orleans, Mayor Nagin issued a mandatory evacuation order for the City. Heavily populated Jefferson parish along with other suburban and rural parishes also called for residents to evacuate. By the time storm conditions reached New Orleans, an estimated 450.000 vehicles had fled the metropolitan region using primary roads (Wolshon 2006, Wolshon et al. 2006) with an estimated additional 10.000-30.000 using secondary roads. Based on these traffic counts, Wolshon (2006a) estimates that 1,1 million people, or 80 to 90 percent of the population at risk in Southeast Louisiana, evacuated the area before the storm. This success is attributed to the effective implementation of a comprehensive, regional phased-evacuation plan.

In addition to the evacuation, local authorities set up various shelters in the city. In St. Bernard Parish, two schools were offered as shelters. In Orleans parish, the Superdome was set up as shelters. Boyd (2006a) estimates that of the 72.000 people who remained in the city after the evacuation an estimated 26.000 individuals sheltered in the Superdome, see also (Anon, 2005a), but later estimates put the number sheltered in the Superdome at 10,000 -12,000 and nearly 68,000 people sheltered through the New Orleans metropolitan area (Boyd 2007.) Initially, the Superdome served it purpose as a shelter-of-late resort well. The problems associated with the Superdome occurred during the post-storm period when tens of thousands of rescued persons arrived creating overcrowded conditions while there were delays before post-storm evacuation assistance arrived.

\subsection{Impact: Levee breaches and flooding}

During its final landfall on August 29, Katrina's storm surge caused massive flooding and devastation along a 170 mile $(\sim 270 \mathrm{~km})$ stretch of the United States Gulf Coast. The entire coastline of the state Mississippi suffered the impacts of the surge and massive destruction. The storm surge also caused massive overtopping and breaching of levees around New Orleans. The flooded area of the city basically consists of three bowls: the central part of the city (Orleans), New Orleans East and St. Bernard, see figure 1. The first flooding of residential areas in greater New Orleans occurred almost two hours before the storm's landfall. The waters flowed into the Orleans bowl to the west, and into the New Orleans East bowl on the east side of the Industrial Canal. Later that morning more catastrophic breaching occurred along the southern arm of the Industrial Canal. Two major breaches in the floodwalls resulted in a rapidly rising and fast moving flood of the St. Bernard bowl with catastrophic consequences. An area of approximately $260 \mathrm{~km}^{2}$ of the city flooded, at some locations more than 4 meters deep. Figure 1 gives an overview of the flooded area and the locations of the levee breaches. It took over 40 days to dewater the 
city. It is worth noting that additional suburban and rural areas also experienced flooding. The three flooded regions described above are significant because of the combined extent of flooding and human exposure resulted in significant loss-of-life.

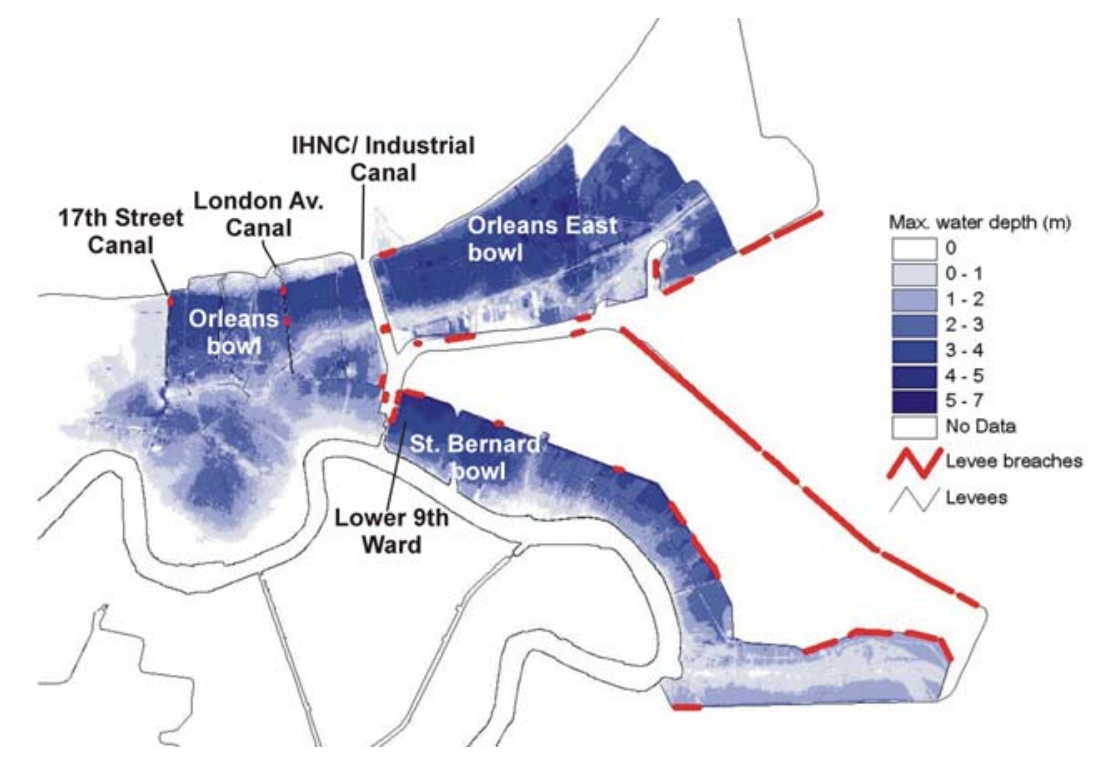

Figure 1: Overview of flooded area, levee breach locations and maximum water depths (Jonkman, 2007)

\section{SIMULATION OF FLOOD CHARACTERISTICS}

\subsection{Introduction}

Several organisations, including the Federal Emergency Management Agency (FEMA) and the Louisiana State University (LSU) Hurricane Center, have made floodmaps that provide insight in the water depths in the flooded parts of New Orleans. These flood maps are based on precision measurements of the extent of flooding, the water surface elevation, and the land elevation. However, for an analysis of flood fatalities, other flood characteristics besides water depth will impact flood deaths (Jonkman, 2007). These include flow velocity, rise rate and arrival time of floodwater (see figure 2). To gain more insight in these flood characteristics, simulations have been made for two of the New Orleans bowls (Orleans and St. Bernard, see figure 1). In these two regions, the violent nature of the flood process created the greatest loss of life. Using the simulation results, we analyse the relationship between the flood characteristics and mortality in section 5. The flood simulations of overland flow have been made by means of a two dimensional hydraulic model, SOBEK-1D2D developed by WL|Delft Hydraulics. Given a number assumptions and limitations regarding the input data it is important to realize the limitations of these simulations. They give a first order insight in flood conditions in the affected area. De Bruijn (2006) and Maaskant (2007) give further background information on the flood simulations.

The simulations show that the most severe conditions occurred in the St. Bernard bowl. Very high flow velocities (3 to $10 \mathrm{~m} / \mathrm{s}$ ) occurred near the catastrophic breaches in the levees along the Industrial Canal (see figure 2). These effects caused destruction in the Lower $9^{\text {th }}$ Ward. Depths in St. Bernard reached 3 to 4 meters in the deepest parts and rise rates were high (>5 m/hr) for most of the area. The Orleans bowl also suffered large water depths. In some locations (especially in the Lakefront area) the water depth was more than 5 meters. However, the flow velocities and rise rates were lower than in St. Bernard. Based on the simulations it is estimated that in the Orleans bowl the flood was less severe in comparison to the St. Bernard bowl. 

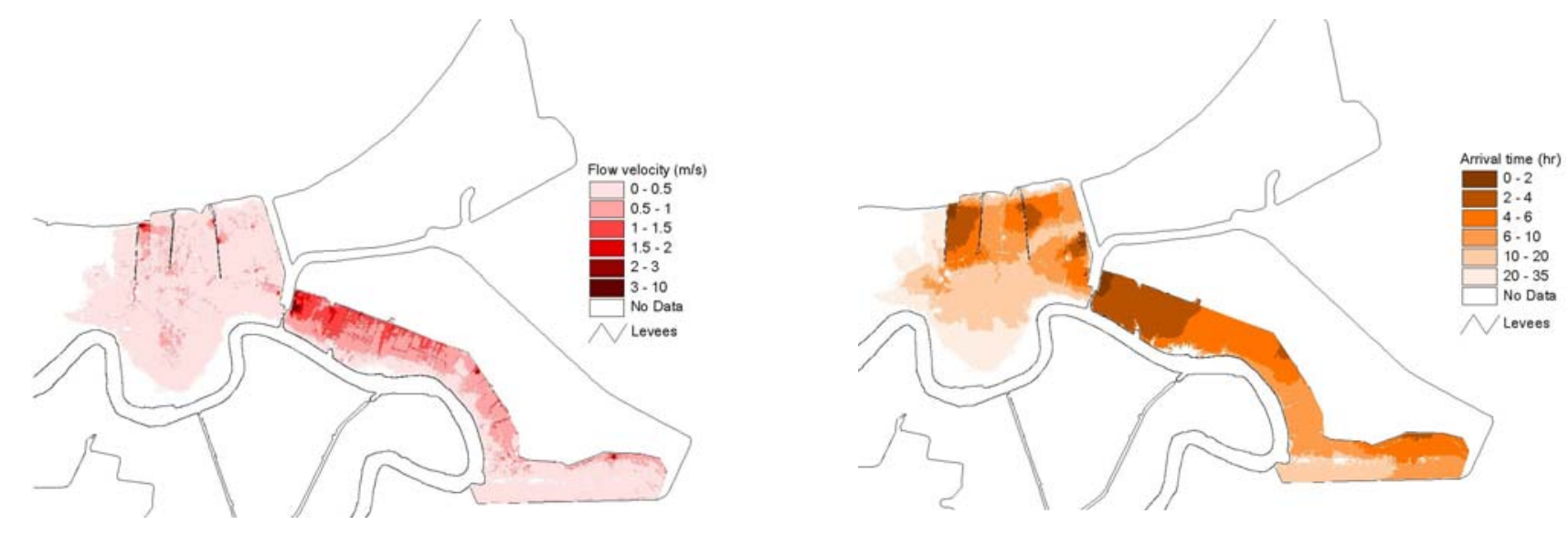

Figure 2: Overview of flow velocity (left) and arrival time of the floodwater (right) after breaching from flood simulations (Jonkman, 2007; Maaskant, 2007)

\section{DATA REGARDING KATRINA RELATED FATALITIES}

In the period after Katrina deceased victims (fatalities) were recovered in a search process that involved several governmental and private organisations. The Department of Health and Hospitals (DHH) of the state Louisiana coordinated the data collection. This agency also provides the official figures on dead and missing on their "Katrina Missing" website ${ }^{1}$. As of August 2, 2006 this site listed 1464 deceased victims and it is noted that the cases of an additional 135 missing have been turned over to law enforcement. Of the confirmed dead, 1118 victims perished within Louisiana, while 346 victims perished outside of the state of Louisiana. At the time of this writing (March 2008, more than two years after the storm) the total list of deceased victims is still incomplete. Some number remain of people are still missing. For over a year following the hurricane, the remains of victims were found sporadically in collapsed buildings and more remote areas, such as the marshes.

\subsection{Dataset of recovery locations}

The LSU Hurricane Center established a collaborative effort with the Department of Health and Hospitals $(\mathrm{DHH})$ and the Medical Examiner's office of the state of Louisiana. As part of this collaboration, $\mathrm{DHH}$ provided the LSU Hurricane Center with data on the recovery locations for the deceased victims (Boyd, 2006b). The most recent dataset, obtained on September 14, 2006, lists 771 fatalities with recovery locations in the state of Louisiana. This corresponds to $69 \%$ of the victims recovered within the state. The recovery locations have been geocoded, i.e. the locations have been identified on a map and entered into a GIS layer. Figure 3 shows the locations where victims were recovered overlayed with the depth of floodwaters.

\footnotetext{
${ }^{1}$ http://www.dhh.louisiana.gov/offices/page.asp?ID=192\&Detail=5248, accessed December 2006.
} 


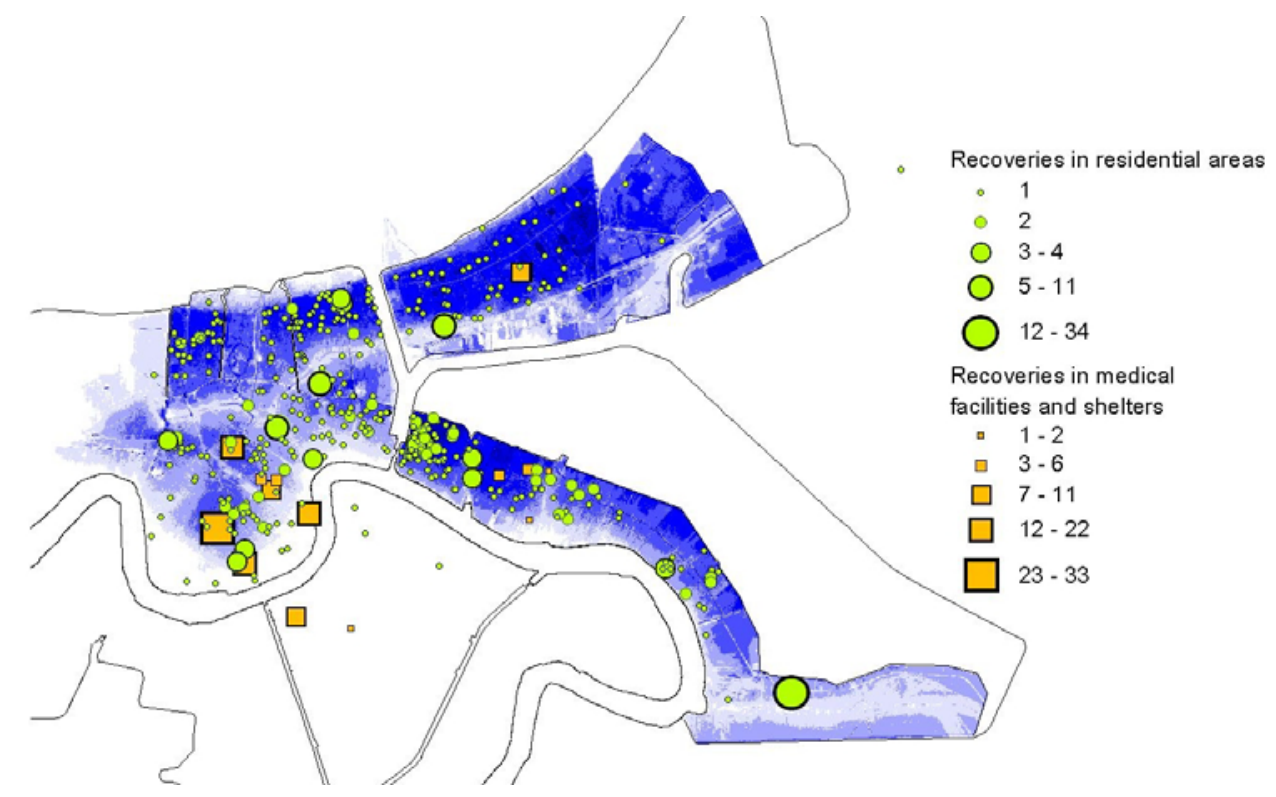

Figure 3: Recovery locations (source: Boyd, 2006b) and flooded area (Jonkman, 2007)

Despite the 135 missing persons and the geocoding of $69 \%$ of the total number of recovered victims, it is expected that the datasets give a representative impression of loss of life caused by hurricane Katrina. Firstly, the majority of recoveries have been completed and the final number of direct fatalities is not expected to grow substantially. Secondly, the dataset includes the majority of recoveries inside the flooded areas and it is therefore expected that it gives a good insight in the spatial distribution of fatalities and the mortality in these areas.

\section{ANALYSIS OF THE RELATIONSHIP BETWEEN FLOOD CHARACTERISTICS AND MORTALITY}

\subsection{General approach}

The number of fatalities caused by a flood event is influenced greatly by the characteristics of the flood (depth, velocity, rise rate), the possibilities for warning, evacuation and shelter, and the loss of shelter due to the collapse of buildings (Jonkman, 2007). It is believed that mortality rates are the highest near breaches and in areas with a large water depth, a high rise rate and a large number of buildings collapsed. In this section the relationship between flood characteristics and mortality in the flooded area is investigated. Mortality is defined as the number of fatalities divided by the number of people exposed to the flooding in that area. The number of people exposed is estimated by using the total number of persons present in the flooded area after the evacuation, with the exclusion of the persons in shelters.

In previous work (Jonkman, 2007; Jonkman et al., 2008) empirical relationships have been developed between the flood characteristics and mortality based on data of historical disasters. These relationships are particularly applicable to floods of low-lying areas that are protected by flood defences. The analysis showed that different zones can be distinguished in an area that floods due to breaching of flood defences. In a zone near the breach(es) flow velocities are high leading to the collapse of buildings and instability of people standing in the flow. In other zones the water depth is one of the most important characteristic and empirical functions have been developed that specify the relationship between water depth and mortality. One other important factor in historical floods was the rise rate. In areas with higher rise rates people are not able to reach shelter on higher grounds or higher floors of buildings. The existing empirical relationships are based on historical flood events that mainly occurred several decades ago, such as the coastal flooding in the Netherlands in 1953. As the consequences of the flooding of 
New Orleans were relatively well-documented these data provide additional insight in the relationship between flood characteristics and mortality.

\subsection{Information on fatalities and the population exposed to floodwaters}

Information regarding fatalities from the dataset of recovery locations has been used. The analysis only includes the fatalities in the flooded area that are expected to be directly associated with the flood conditions, i.e. the recoveries in residential locations and public buildings (figure 3). Fatalities in medical locations and shelters are not included in the analysis because these are generally not directly related to the physical flood impacts.

The population at risk is defined as the original population in the area prior to hurricane Katrina. Due to the effects of evacuation and shelter the number of exposed was reduced before the hurricane. Based on the analysis of traffic counts it is estimated 80 to 90 percent of the 'at risk' population in Southeast Louisiana evacuated the area before the storm (Wolshon, 2006a, 2006b). In this study we assume an evacuation rate of 80 percent for New Orleans, consistent with public statements by local officials. In addition, based on available descriptions, it is assumed that another 10 percent found shelter in special facilities, such as the Superdome or various highschools. This results in an estimate of the exposed population in the flooded area of approximately 10 percent of the inhabitants, corresponding to approximately 44.000 people exposed (see table 1 ). In this analysis it is assumed that the spatial distributions of the evacuated and shelter fractions are uniform. In practice there might have been differences in evacuation rates between neighbourhoods, but precise information regarding the Katrina evacuation has been difficult to obtain. Overall, given the limited amount of data the above estimates are crude, but they give a first indication.

From the data on the flood exposed population and the flood fatalities, it is possible to estimate the average flood mortality for every bowl (see table 1). In the next section, statistical analysis is used to assess how the flood characteristics correlate with the flood mortality.

Table 1: Overview of number of inhabitants, exposed and fatalities for the three flooded bowls

\begin{tabular}{|l|c|c|c|c|}
\hline Bowl & $\begin{array}{c}\text { Inhabitants } \\
\text { (flooded area) }\end{array}$ & Exposed & $\begin{array}{c}\text { Recovered nr. of } \\
\text { fatalities* }\end{array}$ & Mortality \\
\hline Orleans & 255860 & 25590 & 260 & $1,02 \%$ \\
\hline St. Bernard & 85420 & 8540 & 190 & $2,22 \%$ \\
\hline New Orleans East & 96290 & 9620 & 68 & $0,71 \%$ \\
\hline Total & 437570 & 43750 & 518 & $1,18 \%$ \\
\hline
\end{tabular}

\subsection{Analysis of the relationship between flood characteristics and mortality}

To analyse the relationship between mortality and flood characteristics it is necessary to specify the spatial unit over which flood mortality and flood characteristics are measured. One of the existing spatial subdivisions of the city and used in this analysis are neighbourhoods. The mortality rate is calculated per neighbourhood and the flood characteristics are averaged over the neighbourhoods.

Because flood simulations are available for the Orleans and St. Bernard bowls the analysis is done for these bowls. Firstly, it is observed that mortality was high in the breach zones characterised by high flow velocities and large numbers of severely damaged and collapsed buildings. For the St. Bernard bowl, these circumstances occurred in the Lower 9th Ward. In this area the (average) mortality was 5,3\%. By approximation this breach zone was characterised by the following values of the depth velocity product: hv $>5 \mathrm{~m}^{2} / \mathrm{s}$. Comparison with available building damage data shows that nearly all buildings were destroyed in these areas. In the Orleans bowl these conditions did hardly appear and did not contribute significantly to mortality. 
For the remaining locations in the Orleans and St. Bernard bowls the following relationship between flood depth and mortality is obtained (eq. 1 and figure 4). The correlation between observations and predictions is $R^{2}=0,42$, which is moderate.

$$
\begin{aligned}
& F_{D}(h)=\Phi_{N}\left(\frac{\ln (h)-\mu_{N}}{\sigma_{N}}\right) \\
& \mu_{N}=5,20 \quad \sigma_{N}=2,00
\end{aligned}
$$

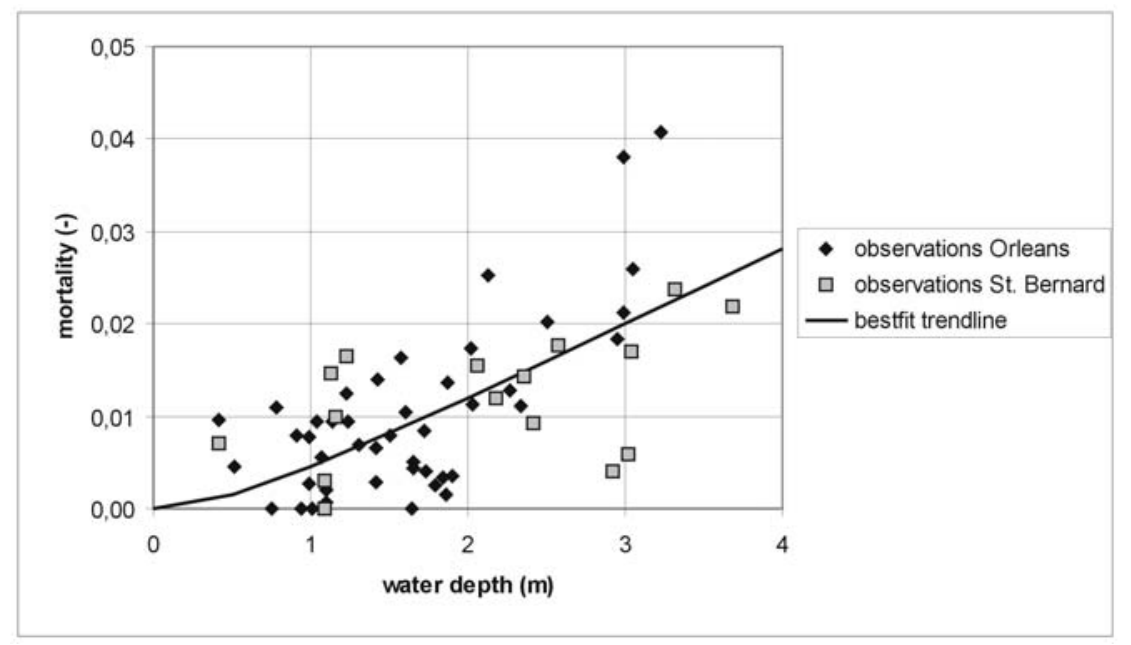

Figure 4: Relationship between water depth and mortality for the Orleans and St. Bernard bowls (Jonkman, 2007)

The available data for the Orleans and St. Bernard bowls do not indicate a clear influence of the rise rate on mortality. Although the rise rates in the Orleans bowl were significantly lower than in the St. Bernard bowl, the relationships between water depth and mortality are very similar for the two bowls. The inclusion of the rise rate in the depth-mortality function does not lead to a better result. Based on the above analyses the derived mortality functions for the flooding of New Orleans are summarized in figure 5.

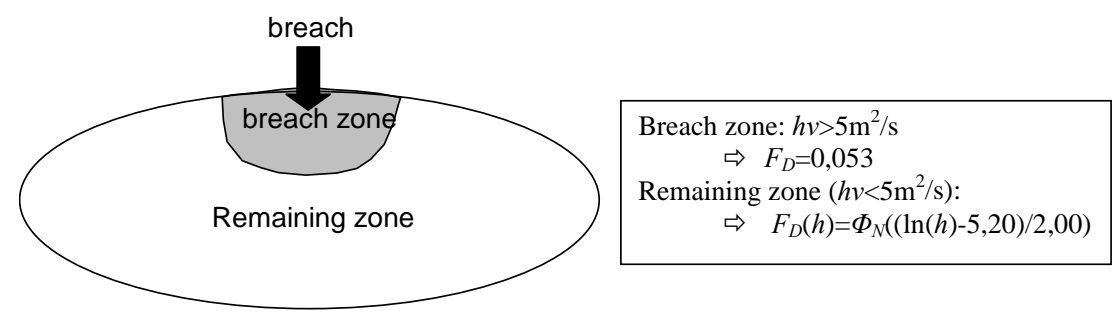

Figure 5: Preliminary mortality functions derived from the data for the flooding of New Orleans

\section{CONCLUDING REMARKS}

A preliminary analysis of the loss of life caused by the flooding of New Orleans after hurricane Katrina in the year 2005 has been presented. Similar to historical flood events, mortality rates were highest in areas near breaches and in areas with large water depths. The highest mortality fractions were observed near the severe breaches in Lower $9^{\text {th }}$ Ward. The earlier proposed approach, in which mortality functions for different zones in a flooded area are distinguished, is also applicable to New Orleans. A relationship has 
been found between the water depth and mortality. One difference with earlier findings is that the preliminary data for New Orleans does not show an influence of the rise rate on mortality.

The presented results and analyses for New Orleans are preliminary: the analysed mortality data are incomplete and several assumptions have been made in the analysis of mortality. Given the above issues, the detailed results regarding the influence of flood characteristics on mortality have to be considered as indicative and preliminary. It is recommended to collect more accurate data regarding fatalities, the exposed population and the flood characteristics. One important factor that deserves further investigation is the influence of the collapse of buildings on mortality. Eventually, based on more complete analyses, an improved method for loss of life estimation may be derived from the New Orleans data in the future. Despite the limitations, the reported results give important insight in the relationship between flood characteristics and mortality. These insights can be used for consequence and risk analyses and as input for decision-making.

\section{REFERENCES}

Anonymous 2005a. 26,000 shelter at the superdome. Times Picayune 28 aug 2005.

Boyd E. 2006a. New Orleans was prepared but it was overwhelmed (correspondence) Nature Vol $442 \mathrm{p}$. 244

Boyd E. (2006b) "Preliminary Summary of Hurricane Katrina fatalities in Louisiana." In The Proceedings

for The 2006 ESRI Public Health GIS Conference. October 25, 2006. Available at

http://gis2.esri.com/library/userconf/health06/docs/summary report.pdf

Boyd E. (2007) "Crescent City Crisis: Recounting a large-scale, urban emergency evacuation." In the

Proceedings for the 2007 ESRI GIS Health Conference. October 7-10, 2007. Available online at

http://gis.esri.com/library/userconf/health07/index.html

De Bruijn K. 2006. Improvement of casualty functions based on data of the flooding of New Orleans in 2005 - preliminary report, WL Delft Hydraulics report Q3668.00

Jonkman S.N. 2007. Loss of life estimation in flood risk assessment, theory and applications, PhD Thesis, Delft University of Technology

Jonkman S.N., Vrijling J.K., Vrouwenvelder A.C.W.M. (2008) Methods for the estimation of loss of life due to floods: A literature review and a proposal for a new method, Natural Hazards, in Press

Maaskant B. 2007. Research on the relationship between flood characteristics and fatalities - based on the flooding in New Orleans caused by hurricane Katrina, Msc. thesis, Delft University of Technology

Stephens K.U., Grew D., Chin K., Kadetz P., Greenough G., Burkle F.M., Robinson S.L., Franklin E.R. (2007) Excess mortality in the aftermath of hurricane Katrina: a preliminary report. Disaster Medicine and Public Health Preparedness Vol. 1 No. 1, pp. 15-20

Wolshon B., Catarella M.A., Lambert L. 2006. Louisiana highway evacuation plan for hurricane Katrina: proactive management of a regional evacuation, ASCE Journal of Transportation Engineering Vol. 132 Issue 1 pp. 1-10 
Wolshon B. 2006. Evacuation planning and engineering for hurricane Katrina, the Bridge Vol. 36 No. 1 pp. 27-34 